\title{
UN NIÑO JESÚS DEL ESCULTOR, PINTOR Y DORADOR DEL SIGLO XVII FRANCISCO DE FONSECA EN SANLÚCAR LA MAYOR (SEVILLA)
}

\author{
A CHILD JESUS IMAGE BY THE $17^{\text {th }}$ CENTURY \\ SCULPTOR, PAINTER AND GILDER FRANCISCO DE \\ FONSECA IN SANLÚCAR LA MAYOR (SEVILLE)
}

\author{
Francisco Amores Martínez \\ Asociación Provincial Sevillana de Cronistas e Investigadores Locales, Sevilla. España \\ famoresm@yahoo.es
}

\begin{abstract}
En la iglesia parroquial de Santa María de Sanlúcar la Mayor (Sevilla) se conserva una imagen del Niño Jesús, que en el presente trabajo documentamos como obra de Francisco de Fonseca, escultor, pintor y dorador activo en Sevilla en las décadas centrales del siglo XVII.

Palabras clave: Francisco de Fonseca; Niño Jesús; siglo XVII; Sanlúcar la Mayor; Sevilla.
\end{abstract}

A Child Jesus image is preserved at the Parish Church in Sanlúcar la Mayor (Seville), which we document in this paper as a work by Francisco de Fonseca, sculptor, painter and gilder active in Seville in the mid- $17^{\text {th }}$ century.

Keywords: Francisco de Fonseca; Child Jesus; $17^{\text {th }}$ century; Sanlúcar la Mayor; Seville.

La representación del Jesús niño desnudo, erguido, en actitud de bendecir con la mano derecha y portando una cruz larga con la otra, tuvo su origen en los Países Bajos a finales del siglo XV, y se difundió rápidamente por toda Europa a través de grabados, un éxito que se debió sin duda a su carácter tierno y amable, pero también a su riqueza teológica, pues reúne en la figura infantil de Cristo al mismo tiempo la exaltación de su Encarnación, Pasión y Resurrección ${ }^{1}$. En la ciudad de

${ }^{1}$ GÓMEZ PIÑOL, Emilio: "El Niño Jesús de la Sacramental del Sagrario Hispalense: introducción al estudio de la génesis de un prototipo distintivo de la escultura 
Sevilla, y en lo que se refiere a la escultura, encontramos un primer hito en la obra que Jerónimo Hernández tallase hacia 1582, según unánime atribución, para la hermandad del Dulce Nombre de Jesús, establecida en el antiguo convento de San Pablo. Posteriormente hay constancia de que su más destacado sucesor en la escuela sevillana de imaginería, Juan Martínez Montañés, concebiría otra imagen que se supone de la misma iconografía en 1596, por desgracia no conservada, mientras que un año después se ha documentado que Blas Hernández hizo otra que tampoco ha llegado a nuestros días, aunque sí una detallada descripción de la misma que responde al modelo citado ${ }^{2}$. Finalmente, en 1606, la Archicofradía Sacramental del Sagrario de la catedral de Sevilla encargaría a Montañés un Niño Jesús que, pese a las modificaciones y restauraciones que ha sufrido a lo largo de su historia, se considera la obra artísticamente más lograda de esta iconografía, la cual fijaría definitivamente un modelo que sería muy imitado durante las siguientes décadas 3 , llegando a ser llamadas "montañesinas" todas y cada una de las representaciones del divino infante que responden a las características descritas, que se hallan repartidas por la geografía española e hispanoamericana. Este encargo serviría además para consagrar una vinculación entre estas imágenes del Niño Jesús y el culto eucarístico, vigente desde el siglo anterior, pero que a partir de entonces muchas hermandades sacramentales de la ciudad y su diócesis acogerían de manera entusiasta, encargando tallas del mismo tipo para sus cultos. Conviene precisar que muchas de las obras conservadas de esta tipología parecen responder a versiones de obras realizadas por otros artistas, que en su mayor parte aún no han sido documentadas, incluidas las no pocas que se atribuyen a Juan de Mesa, principal discípulo de Montañés, algunas de ellas de calidad muy notable. El presente trabajo pretende contribuir modestamente a paliar ese vacío historiográfico, para lo cual damos a conocer, documentando su datación y autoría, una de estas imágenes del Niño Jesús, la que se venera en la iglesia parroquial de Santa María de la ciudad de Sanlúcar la Mayor (Sevilla).

La cofradía del Santísimo Sacramento de la parroquia de Santa María la Mayor de Sanlúcar, la más ilustre de las tres corporaciones eucarísticas que llegó a haber en la ciudad, ya existía en 1573, cuando el bordador sevillano Pedro de Mesa realizó para ella un guión de terciopelo carmesí bordado en oro. $\mathrm{Su}$ vida fue floreciente al menos hasta 1792. Fue reorganizada en 1846 tras un periodo

sevillana”, en RAMOS SOSA, Rafael (dir.): Actas del Coloquio Internacional El Niño Jesús y la infancia en las artes plásticas, siglos XV al XVII. IV centenario del Niño Jesús del Sagrario. 1606-2006. Sevilla, 2010, pp. 17-18.

${ }^{2}$ LÓPEZ MARTÍNEZ, Celestino: Desde Martínez Montañés hasta Pedro Roldán. Sevilla, 1932, pp. 232 y 50-51.

${ }^{3}$ RECIO MIR, Álvaro: "La difusión de los modelos montañesinos del Niño Jesús. Causas de una producción seriada", en RAMOS SOSA, R. (dir.): Actas del Coloquio Internacional El Niño Jesús..., op. cit., pp. 261-285. 
de declive y, con muchos altibajos, ha logrado sobrevivir hasta nuestros días ${ }^{4}$. En los siglos del Barroco organizaba una octava tras la fiesta del Corpus, que finalizaba con una función solemne, y se ocupaba además de llevar de manera periódica y solemne el Santísimo Sacramento a los vecinos que lo solicitaban. Es muy escasa la documentación que se ha conservado de esta corporación, más que algunas referencias indirectas y un libro de cuentas que abarca casi todo el siglo XVII. Gracias al mismo sabemos que en el periodo comprendido entre los años 1636 y 1642 la cofradía llevó a cabo una importante tarea de renovación patrimonial, probablemente la más intensa de toda su historia, en base a una saneada situación económica que no volvería a conocer en mucho tiempo ${ }^{5}$. Según lo recogido en la data de las cuentas correspondientes al trienio 1636-1639, tomadas al prioste Juan Garracín, que desempeñaba el cargo al menos desde 1620, la hermandad encargó entonces en Sevilla una imagen del Niño Jesús para que formase parte de los cultos que celebraba la misma en torno a la fiesta del Corpus Christi, siendo alcalde Cristóbal de Morales, mayordomo Antón Prieto, diputados Pedro de la Parra y Pedro García y escribano Jerónimo Martínez. Así lo atestigua el siguiente registro: "Mas se le descargan veinte y ocho ducados que pagó a $\mathrm{frc}^{\circ}$ de fonseca por la hechura del niño JHS. Certificolo yo Gerónimo Martínez". Diversos indicios nos permiten suponer que la adquisición de la imagen del Niño debió hacerse al final de ese periodo, es decir en los últimos meses de 1638 o los primeros de 1639, siendo así que en los meses siguientes se acometió la realización de un lujoso vestido de tela roja bordada en plata para el divino infante y unas andas con sus faldones para sacarlo en procesión. En el marco de esta renovación patrimonial, se acometió en esas mismas fechas la hechura de nuevas piezas para el culto, como los dos faroles y las "cornucopias y espabiladeras" de plata que hizo el platero de mazonería Blas de Lara, un paño de sobremesa que bordó Juan de Beas, otro paño para el sagrario, tres frontales de altar y un escaño de madera para la junta de oficiales, y asimismo se procedió a enriquecer el "pellico" o vestido de una imagen infantil de San Juan Bautista con que contaba la corporación y que por desgracia no se conserva, y a platear la vara del guión de gala y restaurar las de madera del palio, el guión ordinario y los candeleros, tarea esta última que llevaría a cabo un tal " $\mathrm{frc}^{\circ}$ de fonseca dorador". En 1640 se estrenaron las tres potencias de plata que deben ser las mismas que aun hoy luce el Niño en su cabeza: "Mas se le descargan sesenta y siete reales que costaron las tres potencias de plata que se hicieron para el niño Jesús, los treinta y cinco que tubieron de peso $\mathrm{y}$ veinte de hechura y los doce restantes del trueque". Aunque su autor en este caso no se menciona, bien podría tratarse del citado Blas de Lara o quizá de otro

${ }^{4}$ CARRETERO MESA, Francisco: La parroquia de Santa María la Mayor de Sanlúcar la Mayor (Sevilla). Sanlúcar la Mayor, 2014, pp. 28-33.

5 Archivo de la Parroquia de Santa María de Sanlúcar la Mayor (A.P.S.M.S.M.), Libro de cuentas de la cofradía del Santísimo Sacramento. 1607-1692, s. f. 
platero, vecino de Sevilla, de nombre Jorge Fernández, que había realizado para la cofradía en 1636 dos "candeleros triángulos de plata" cuyo coste fue de más de trescientos reales. Finalmente, en el año 1642 se estrenó la peana de madera sobre la que se asienta el Niño, que costó ochenta reales, y por cuyo dorado se pagaron otros sesenta a " $\mathrm{frc}^{\circ}$ de fonseca, dorador", lo cual, junto a dos nuevas varas de plata para los alcaldes, hizo que quedase completado el patrimonio de la cofradía, que no sufriría variaciones significativas durante lo que restaba del siglo.

Cuestión importante que debemos dilucidar es si el Francisco de Fonseca que se menciona como autor de la hechura del Niño es el homónimo personaje citado un poco más adelante como el artífice que se encargó de platear la vara del guión de la cofradía y poco tiempo después de dorar la urna o peana para la imagen. Hay que señalar que solo se conoce actualmente una referencia documental alusiva a un imaginero de ese nombre activo en Sevilla en el siglo XVII. Se trata de un documento notarial fechado el 23 de mayo de 1667, mediante el cual Francisco de Olivares arrendaba una casa situada en la Alameda de Hércules a Juan de Aragón y Juan Joseph, maestros doradores, actuando en el acto como fiador "Francisco de Fonseca, maestro escultor vecino de esta ciudad en la collación de San Martín"6. Por nuestra parte hemos cotejado la firma de Fonseca en este documento con la que aparece en otro fechado el 30 de agosto de aquel mismo año, en este caso una carta de pago que daba "Francisco de Fonseca, pintor de imaginería y encarnador y estofador", vecino de la collación de San Martín ${ }^{7}$, y debemos decir que las firmas son absolutamente idénticas en ambos documentos, por lo que podemos asegurar que el maestro escultor Francisco de Fonseca y el pintor de imaginería y dorador Francisco de Fonseca son una misma persona. Suponemos que el hecho de que recurriese, por única vez conocida, al título de escultor que legítimamente poseía aunque no ejerciese habitualmente como tal, pudo deberse a que por alguna razón quizá de índole legal no quería figurar como colega de profesión en el mencionado contrato de alquiler firmado por dos maestros de su mismo gremio de doradores, uno de los cuales además había sido discípulo suyo. Por lo demás no se trata de un caso aislado, pues es conocida la dedicación circunstancial a la escultura de otros pintores en la Sevilla de los Siglos de Oro, como sería el caso de Pedro de Campaña ${ }^{8}$ o Juan de Valdés Leal ${ }^{9}$, o de doradores

${ }^{6}$ Archivo Histórico Provincial de Sevilla (A.H.P.Se.), sec. Protocolos Notariales, of. 1, 1667, lib. 2. ${ }^{\circ}$, leg. 587, f. 259.

7 A.H.P.N.Se., of. 19, 1667, lib. 3. ${ }^{\circ}$, leg. 12.980, f. 65.

8 PACHECO, Francisco: Libro de descripción de verdaderos retratos de ilustres y memorables varones. Se cita por la edición de PIÑERO RAMÍREZ, Pedro y REYES CANO, Rogelio. Sevilla, 1985, p. 292.

9 RODA PEÑA, José: "Valdés Leal, escultor. Aportación a su catálogo", Laboratorio de Arte, 14, 2001, pp. 51-64. 
y estofadores como Baltasar Quintero ${ }^{10}$, por citar algunos de ellos. En otro orden de cosas, creemos estar en condiciones de adivinar el motivo por el cual la hermandad del Santísimo que nos ocupa eligió a Fonseca y no a otro imaginero hispalense para que tallase su Niño Jesús, y no es otra que su vinculación familiar con la ciudad de Sanlúcar la Mayor, pues nos consta que el padre de su esposa Beatriz de Castro había sido vecino de dicha localidad, donde la familia poseía unas casas que se encargaría precisamente Fonseca de vender en $1652^{11}$.

No son escasos los datos biográficos que conocemos acerca de este artista, quien, según declaración propia, había nacido en la localidad de Loñoa, perteneciente entonces al obispado de la ciudad portuguesa de Lamego ${ }^{12}$, una población que en la actualidad es una pequeña aldea de las que configuran la villa de Pereiro de Aguiar, ubicada en la zona suroriental de la provincia española de Orense. Fueron sus padres Diego de Fonseca y Felipa Rodríguez. Debió trasladarse en la segunda o tercera década del siglo XVII a Sevilla, donde tras una etapa de aprendizaje y el preceptivo examen gremial abriría un obrador en el que ejercería sobre todo como dorador y estofador, aunque también pero de manera esporádica como pintor y escultor. Habría que situar por tanto a Fonseca en el grupo de pintores y doradores portugueses que entre 1600 y 1630 llegaron a la ciudad con la intención de aprender el oficio con los prestigiosos maestros locales, constituyendo la tercera comunidad extranjera de pintores que trabajó en Sevilla en aquella época ${ }^{13}$. Se estableció Fonseca en el barrio de San Martín y contrajo matrimonio con Beatriz de Castro, con la que engendró al menos un hijo de nombre Nicolás, quien heredaría el oficio de su padre ${ }^{14}$. En la misma collación permanecería el resto de su vida, en una casa que al parecer se hallaba situada frente al hospital del Amor de Dios, y a espaldas del palacio de los Saavedra. Sabemos por otra parte que fue miembro de la Congregación del Santísimo y Doctrina Cristiana, establecida en la Casa Profesa de la Compañía de Jesús, en la cual ingresó en $1669^{15}$. Su fallecimiento debió producirse no mucho tiempo después del mes de mayo del año 1674, fecha de la que data el último testimonio documental

${ }^{10}$ DÍAZ HIERRO, Diego: "Baltasar Quintero. Arquitecto de retablos, pintor y escultor", Archivo Hispalense, 134, 1965, pp. 303-308.

${ }^{11}$ KINKEAD, Duncan T.: Pintores y doradores en Sevilla 1650-1699. Documentos. Bloomington, 2006, p. 180.

12 Ibidem, p. 184.

13 MÉNDEZ RODRÍGUEZ, Luis: "Una aproximación al estudio de los pintores extranjeros en la Sevilla del Siglo de Oro", en Actas del I Coloquio Internacional Los Extranjeros en la España Moderna. T. II. Málaga, 2003, pp. 537-539.

${ }^{14}$ KINKEAD, D.: Pintores y doradores en Sevilla..., op. cit., p. 184.

15 GESTOSO Y PÉREZ, José: Ensayo de un diccionario de los artifices que florecieron en Sevilla desde el siglo XIII al XVIII inclusive. T. I. Sevilla, 1899, p. 142. 
conservado, consistente en el cambio de su morada a otras casas situadas "en la costanilla de San Martín"16.

La producción conocida de Fonseca como dorador de retablos y estofador de imágenes, que abarca un arco cronológico que va desde el año 1638 hasta el de 1670, pone de manifiesto el notable prestigio que alcanzó en aquellas décadas centrales del siglo, pues llegó a ser reclamado desde diversas localidades del occidente andaluz. En la capital hispalense laboró para algunas de sus más importantes instituciones, y en todos estos encargos trabó una fecunda relación personal y profesional con algunos de los principales nombres del panorama pictórico y escultórico de la Sevilla barroca. La mayor parte de la documentación conocida hace referencia a su actividad como dorador de retablos, siendo el primero de ellos el de la capilla de la Virgen de los Remedios de Villarrasa (Huelva), de 1652, al que sigue el mayor de la iglesia conventual de Santa Clara de Carmona, en 1653, mientras que el año siguiente se ocupaba de dorar el mayor del igualmente templo conventual de Santa Ana de Montilla (Córdoba) ${ }^{17}$. Muy significativa, porque alude a que nuestro artífice se hallaba ya plenamente integrado en los círculos artísticos hispalenses, es la de que en octubre del año 1657 se obligaba notarialmente junto a los escultores Francisco de Ribas y José de Arce y el ensamblador Manuel de Segovia a correr con la obra del retablo mayor de la iglesia colegial de Zafra (Badajoz), en caso de que incumpliera su obligación Blas de Escobar, quien lo había contratado un mes antes ${ }^{18}$. En 1653 fue llamado por una prestigiosa corporación, la Archicofradía Sacramental del Sagrario de la catedral de Sevilla, para "encarnar" la ya citada imagen de su Niño Jesús ${ }^{19}$, y por las mismas fechas llevaba a cabo otro trabajo de dorado en una capilla del hospital de las Cinco Llagas ${ }^{20}$. Siguiendo en la capital, sabemos que en agosto de 1659 Fonseca se comprometía a dorar el arco toral de la iglesia del convento Casa Grande de la Merced, importante encargo al que seguiría en mayo de 1660 el del dorado del segundo cuerpo del retablo que el ya citado Francisco de Ribas había labrado en la capilla del Sagrario de la iglesia de San Juan de la Palma por encargo de su cofradía sacramental, así como a realizar la misma labor en un arco del altar de la Virgen de la Antigua del mismo templo ${ }^{21}$. En junio de 1661 se obligaba a dorar un

${ }^{16}$ KINKEAD, D.: Pintores y doradores en Sevilla..., op. cit., p. 184.

17 LÓPEZ MARTÍNEZ, Celestino: Desde Martínez Montañés hasta Pedro Roldán. Sevilla, 1932, p. 183.

${ }_{18}$ KINKEAD, D.: Pintores y doradores en Sevilla..., op. cit., pp. 180-181.

19 ILLÁN, Magdalena y VALDIVIESO, Enrique: Noticias artísticas sevillanas del archivo Farfán Ramos: siglos XVI, XVII y XVIII. Sevilla, 2005, pp. 166-167.

${ }^{20}$ HERNÁNDEZ DÍAZ, José: Documentos para la historia del arte en Andalucía. T. I. Sevilla, 1927, p. 148.

${ }^{21}$ SANCHO CORBACHO, Heliodoro: "Artífices sevillanos del siglo XVII", en Homenaje al Prof. Dr. Hernández Díaz. T. I. Sevilla, 1982, pp. 631-632. 
retablo dedicado a San Juan Evangelista y ubicado en el claustro del monasterio de Santa María de las Dueñas, una obra en la que Fonseca se comprometió también a poner "dos lienzos de pintura de la advocación y historia que pidiera la dicha doña Elvira Maldonado"22, noticia interesante que nos habla de la habilidad del artista como pintor y de su dedicación circunstancial a este arte, un ámbito en el cual su producción es por el momento prácticamente desconocida, como lo era hasta ahora la de carácter escultórico. De la década de los años sesenta datan sus tres últimos trabajos conocidos, cuales son el dorado de un retablo en la iglesia del convento de San Agustín en 1665, el del retablo que poseía la cofradía de la Pura y Limpia Concepción de la villa de Osuna en 1668, y finalmente, en 1670, el dorado del retablo mayor de la iglesia del ya citado monasterio sevillano de Santa María de las Dueñas ${ }^{23}$, obra de notable envergadura propia de una artista que se hallaba en el cénit de su carrera. El prestigio que llegó a alcanzar entre su gremio le llevaría a acoger en su obrador al menos a dos aprendices, el primero de ellos Juan José de Salinas, que llegó allí en julio de 1652 con catorce años de edad, y el otro Cristóbal Nieto, quien hizo lo propio en abril de $1660^{24}$.

El Niño Jesús que concibió Francisco de Fonseca para la cofradía del Santísimo de Sanlúcar responde fielmente al prototipo iconográfico que hemos glosado anteriormente (Figuras 1-4). Mide $72 \mathrm{~cm}$ y se eleva como es preceptivo sobre un delgado cojín, que a su vez asienta sobre una alta y sobria peana de perfiles rectilíneos, apenas decorada con pequeñas costillas en la parte superior, alcanzando la obra con este elemento una altura total de un metro. Con la mano izquierda sujeta una cruz de plata muy fina, con tres travesaños horizontales terminados en pequeñas perillas, una original pieza de la cual no hemos hallado referencia documental alguna. En la cabeza ha desarrollado Fonseca su personal creatividad, pues al tratarse de una imagen para ser vestida era la parte de la misma que iba a estar sometida de manera permanente a la contemplación de los fieles, y aparece orlada por tres potencias de plata que bien pueden ser las estrenadas en 1640, con galleta que presenta una cartela conformada por ces, de la que parten haces de rayos rectos. Pero no se ha descuidado la talla del cuerpo, que podemos calificar como algo más que correcta, tanto en sus proporciones como en el tratamiento anatómico, consiguiendo el artista una figura esbelta en la que sobresale el logrado contraposto que origina la flexión de la pierna derecha y el pie ligeramente levantado. Por su parte, la cabeza muestra unos rasgos contundentes, cubierta por una cabellera de perfil marcadamente triangular, que ha sido trabajada en amplios mechones, con alto y poblado copete central sobre una frente

${ }^{22}$ LÓPEZ MARTÍNEZ, Celestino: Retablos y esculturas de traza sevillana. Sevilla, 1928 , pp. 24-25.

${ }^{23}$ KINKEAD, D.: Pintores y doradores en Sevilla..., op. cit., pp. 183-184.

${ }^{24}$ Ibidem, pp. 180, 182, 391-393 y 486-490. Salinas llegaría a detentar puestos directivos en el gremio de pintores y doradores en los años finales del siglo XVII. 
amplia y despejada, características que recuerdan a las de otro Niño Jesús, perteneciente a la colección Morales Marañón y atribuido por el profesor Recio Mir a Martínez Montañés, excelente obra que a su juicio podría ser de factura anterior al del Sagrario de la catedral hispalense ${ }^{25}$. Por su parte, el rostro de la figura, con la simetría de sus elementos, la mirada baja y la boca cerrada, muestra una expresión ensimismada que invita al espectador a penetrar en el profundo misterio que representa. Posee ojos de cristal que se le debieron colocar en una intervención no documentada de finales del siglo XVIII o comienzos del XIX, momento en el que probablemente se retocase la policromía, fundamentalmente en el rostro, precisamente la zona donde su estado actual es más deficiente junto con las manos. Nos encontramos por tanto ante una obra eficazmente resuelta y realizada por un escultor de talento quizá no sobresaliente pero que hace gala de una formación sólida, que no alcanza la perfección de las que se atribuyen a los principales maestros de la escuela pero que a nuestro juicio supera claramente las obras seriadas que tanto abundaron en aquella época. La imagen ocupó desde su hechura un lugar destacado en el templo parroquial de Santa María, siendo entronizada en el manifestador del retablo mayor desde que el mismo fuese estrenado el año 1700. Además de los testimonios gráficos existentes, documentalmente podemos respaldar lo antedicho con el testimonio del párroco Eusebio Romero, quien en un inventario realizado en 1904 declaraba, refiriéndose al altar mayor, que "cuando no hay Exposición del Santísimo ocupa ordinariamente el trono o manifestador un Niño Jesús tallado de un metro de alto, con sus potencias de plata y una cruz en la mano también de plata" ${ }^{26}$. En ese lugar ha permanecido hasta hace pocos años, en que ha sido colocado sobre una peana en el muro del lado de la epístola, habiendo sido sustituido en el retablo mayor por otra imagen más pequeña de otro Niño Jesús, procedente de una colección particular sanluqueña.

Fecha de recepción: 29 de septiembre de 2016

Fecha de aceptación: 4 de enero de 2017

${ }^{25}$ RECIO MIR, Álvaro: “Juan Martínez Montañés. Niño Jesús”, en PLEGUEZUELO HERNÁNDEZ, Alfonso y VALDIVIESO GONZÁLEZ, Enrique (com.): Teatro de Grandezas. Granada, 2007, pp. 232-233.

${ }^{26}$ Archivo General del Arzobispado de Sevilla (A.G.A.S.), Administración General, Inventarios, leg. 14.562, exp. 15. 


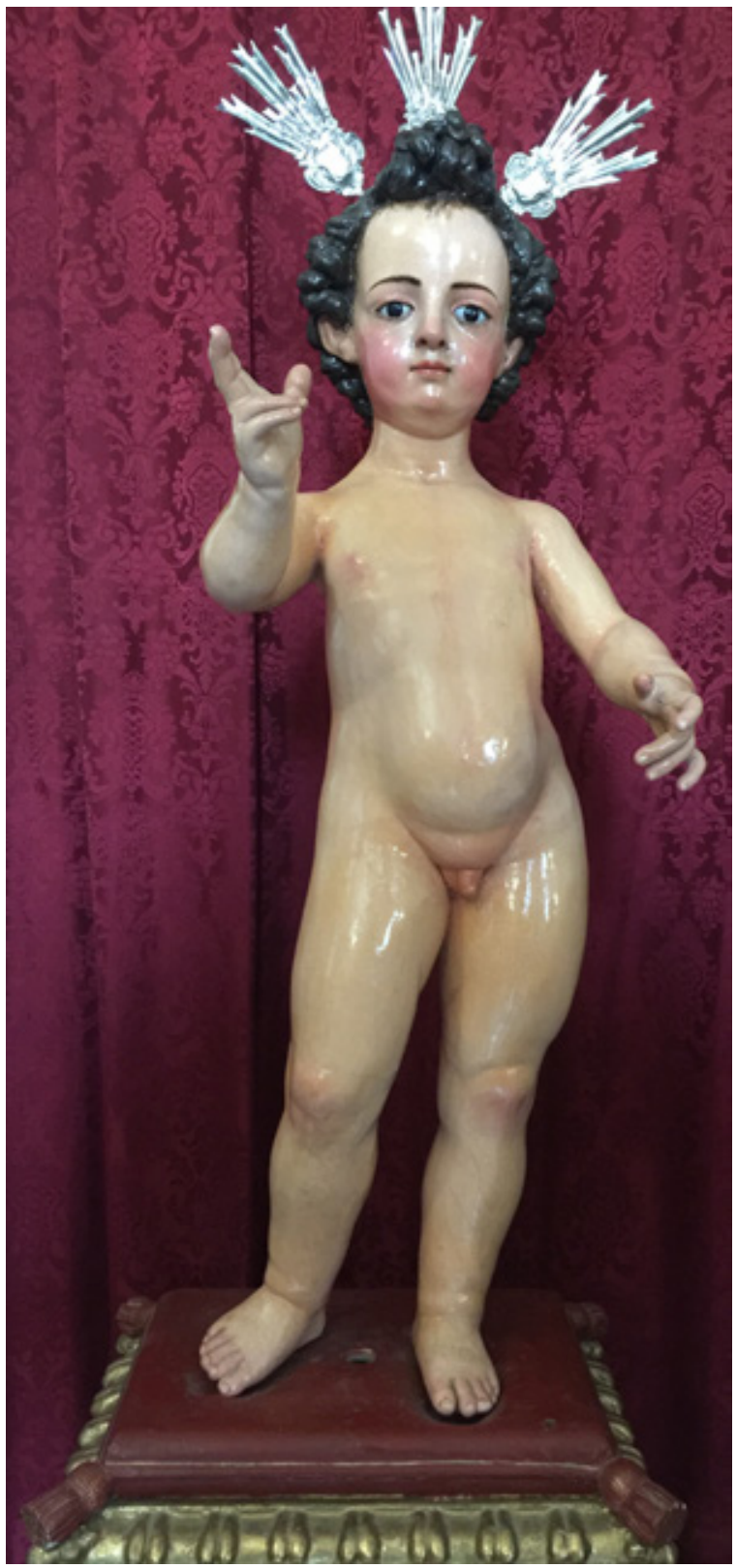

Figura 1. Francisco de Fonseca, Niño Jesús, hacia 1638-1639, parroquia de Santa María la Mayor, Sanlúcar la Mayor (Sevilla).

LABORATORIO DE ARTE 29 (2017), pp. 287-298, ISSN 1130-5762 e-ISSN 2253-8305 - DOI http://dx.doi.org/10.12795/LA.2017.i29.15 


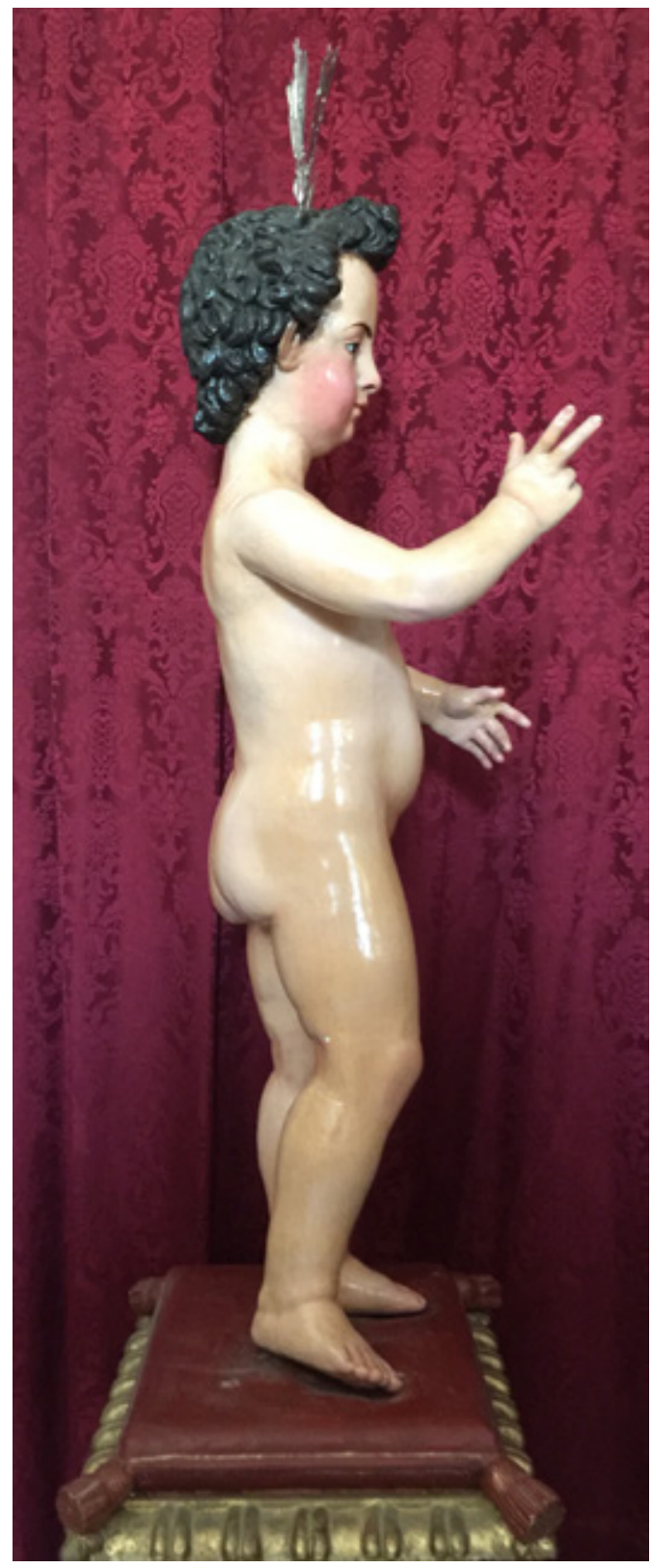

Figura 2. Francisco de Fonseca, Niño Jesús, hacia 1638-1639, parroquia de Santa María la Mayor, Sanlúcar la Mayor (Sevilla). 


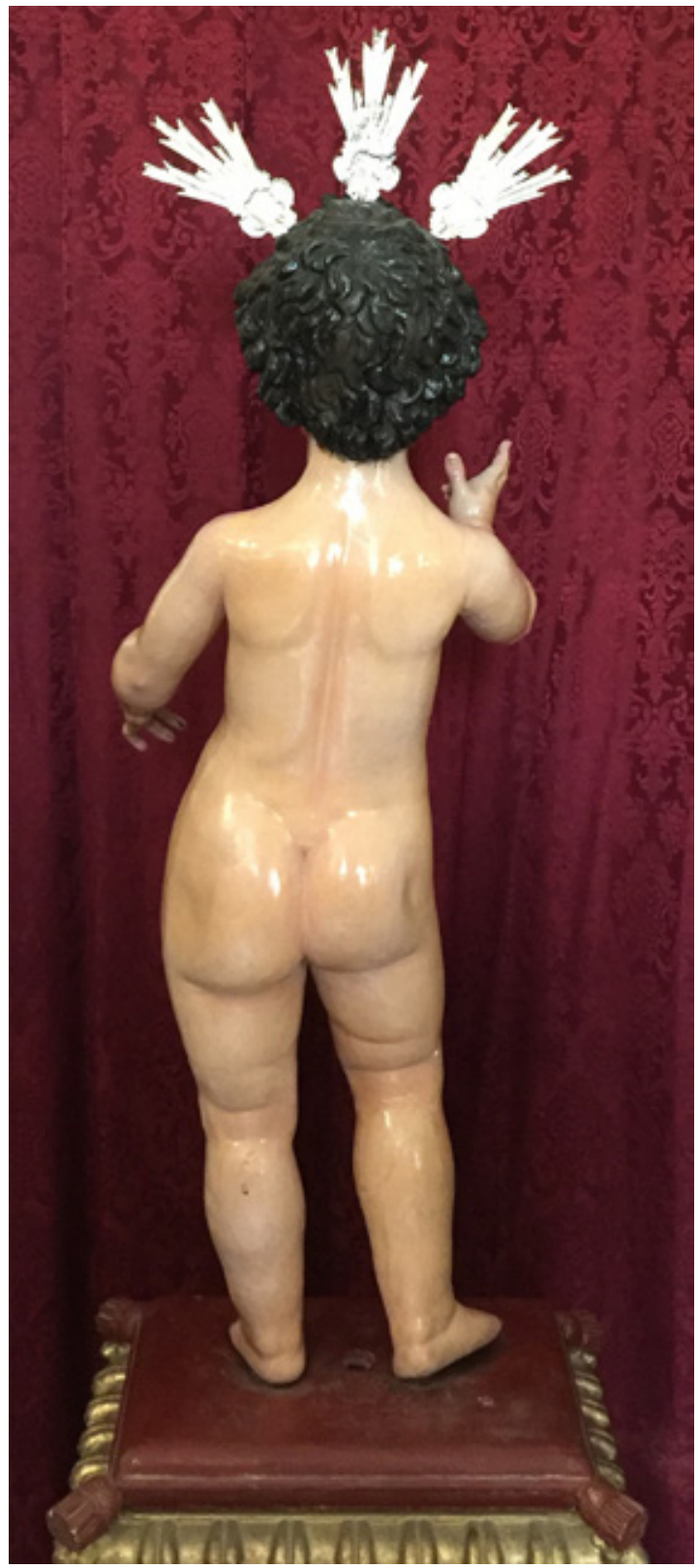

Figura 3. Francisco de Fonseca, Niño Jesús, hacia 1638-1639, parroquia de Santa María la Mayor, Sanlúcar la Mayor (Sevilla). e-ISSN 2253-8305 - DOI http://dx.doi.org/10.12795/LA.2017.i29.15 


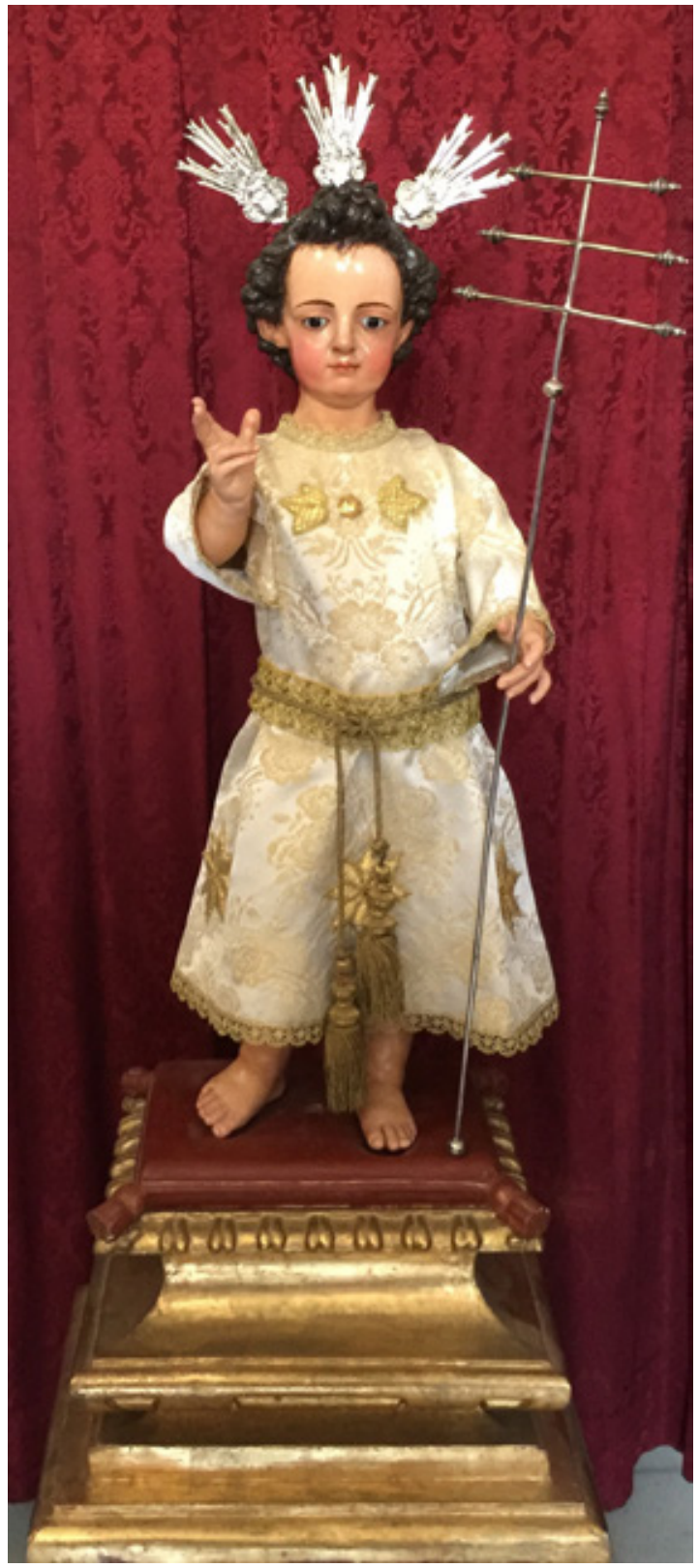

Figura 4. Francisco de Fonseca, Niño Jesús, hacia 1638-1639, parroquia de Santa María la Mayor, Sanlúcar la Mayor (Sevilla). 